\title{
Discussion on the Development Trend of Computer Science and Technology
}

\author{
Ding Juan \\ NanChang Institute of Science \& Technology
}

\begin{abstract}
Computer and our life is increasingly dependent on computer technology, our life, learning has changed a lot. As a kind of important science and technology, computer information technology is at an unprecedented pace of development into people's lives step by step and is gradually applied to every field of human society. For nearly a century, with the unprecedented speed, computer technology has been widely applied to industrial production and other fields, in various fields plays an important history. This paper begins with the current situation of computer development, analyzes the reasons of the rapid development of computer technology, and then expounds the development of computer science and technology from two aspects: the intelligent supercomputer, the new high performance computer, and then summarizes the development trend of computer science and technology.
\end{abstract}

Keywords-Computer; Computer Science; Development Trend

\section{INTRODUCTION}

From the perspective of human history, the development of computer science and technology is the need of the development of the society. Computer technology is the product of the third industrial revolution after the Second World War, and every country began to develop economy after World War II, so the computer was born in the industrial revolution. The birth of the computer brought the human into the information age. With the tide of economic integration, the world is more closely linked, and today's world is an open world, countries have opened the door to strengthen the link between countries, and computer science and technology has played an important role in the country, will be different countries, different regions of the country closely linked.
Computer technology is the product of the third industrial revolution after World War II, taking technology of the computer as the third industrial revolution led more than twice before the industrial revolution more momentous can be technically amazing development speed of the computer, the science and technology popularization so widely, is unprecedented in human history, information technology plays an irreplaceable role in breathtaking.

\section{ANALYSIS OF THE REASON OF THE DEVELOPMENT OF COMPUTER SCIENCE AND TECHNOLOGY}

\section{A. Need of the Development of Society}

From the perspective of human history, the development of computer science and technology is the need of the development of the society. Computer technology is the product of the third industrial revolution after the Second World War, and every country began to develop economy after World War II, so the computer was born in the industrial revolution. The birth of the computer brought the human into the information age. Today's world is an open world, countries have opened the door to strengthen the link between countries, and computer science and technology in which play an important role in the country, different countries, different regions of the country closely linked.

\section{B. Need of Information Sharing}

Computer science and technology has brought human beings into the information society, the information sharing, and the information sharing of the carrier is the computer science and technology. The relationship between computer technology and information sharing is very close. Information sharing is the basis. The computer 
science and technology is the carrier, and through the computer system platform to achieve information sharing. Computer science and technology has realized the transmission and sharing of information, especially in today's increasingly close social background, the exchange between countries is increasingly close, more and more cooperation and exchange activities, the need to deal with a wide variety of transactions, which is applied to the computer science and technology to achieve information sharing, so that the country and society to deal with affairs more convenient and quick.

\section{THE DEVELOPMENT TREND OF COMPUTER}

\section{A. Super Computer}

The ultra-fast computer uses the parallel processing technology to improve the computer structure, so that the computer system executes a plurality of instructions for processing the data to further improve the running speed of the computer. Super computers can complete the general computer and server cannot calculate the large complex tasks, for the aerospace industry, government, large enterprises, weather, and natural geographic simulation and so on big data areas.

\section{B. Intelligent Computer}

The high speed volume and small computer provide the possibility for the application of the intelligent, more and more artificial intelligence products are developed to meet the needs of different users. More intelligent computer, rich and convenient for our life, they are very sensitive to the customer experience, often in a very short time, in order to meet the needs of customers, and to update the new products and services to better meet customer experience.

\section{New Computer}

Quantum computer, photon computer, molecular computer, nanometer computer, these computers are different from people's current computer equipment. For example, the calculation process of molecular computer is the interaction process between protein molecules and the surrounding physical and chemical mediators. The information storage structure of a new type of computer is different from the general computer using electronic, but the use of quantum, photons, molecules, and nano materials technology, etc.

\section{Internet and Cloud Technology}

Internet and cloud technology is undoubtedly an important branch of computer technology in the present, the future development of this field is also bound to be better than the other. Each of our individual needs of the huge demand for the Internet and cloud technology to provide a strong driving force, IT enterprises in the process of meeting these needs to obtain an objective profit, which also makes the enterprise more actively promote new products and services, improve the original technology development computer technology.

\section{The SPECIFIC DEVElopment TREND of COMPUTER SCIENCE AND TECHNOLOGY}

\section{A. High Speed Computer}

Air is a colorless, tasteless touch less than the material, but has a tremendous impact on human beings. We all know that air is a very good insulating material, and then use the air which is a non-conducting properties to improve the running speed of the computer is a best of both worlds thing, so to get a computer to start operation of raw material is convenient, to make the effective use, not damaged by the pollution of the air and saves the material cost, is a worthy of popularization of research and development of a computer science and technology.

\section{B. Optical Computer}

As is known to all, light is also an important material that can be used to generate electricity. Today, the use of light energy as a cell phone, and the future use of computer information data transmission is a major trend in the development of computer science and technology. Optical computer material is also very convenient to obtain, in high temperature and other conditions are still capable of normal operation 


\section{C.Nano Computer}

The future of computer volume will be smaller and smaller, and even appear to nano computer. Not only in the study of scientific experiments, will be higher in the field of application.

\section{Super Intelligent Computer}

Intelligent supercomputer focus is intelligent, its design structure will be more independent, the use of new parallel processing technology, can be more than one instruction data processing. Its performance is far beyond people's imagination, the ability of information processing beyond people's expectations, through the experimental simulation of the model, can easily analyze the data.

\section{V.CONCLUSION}

To sum up, we can see that the computer technology is mainly in the three direction of development:

One is to "high" direction. Performance is getting higher and higher, faster and faster, the main performance in the computer's main frequency. Parallel computers are more parallel than general-purpose machines. The key technology of parallel computers is how to connect a large number of computers to each other, that is, the high-speed communication between the processors and how to effectively manage thousands of computers.

Another direction is to "wide" in the direction of development, the trend of computer development is everywhere, so that like "no computer". In recent years, the trend is more evident in the network and the penetration of the various fields, that is, the development of the breadth of the development. This trend is called universal computing or ubiquitous computing.

The third direction is to develop in the direction of "deep", that is, the intelligent development of the information. There is a lot of information online, how to put things into a broad array of knowledge you want, this is the important subjects in computer science and human-computer interface more friendlily.

\section{REFERENCES}

[1] Sarrafzadeh M. Department Of Electrical Engineering And Computer Science[J]. Journal of Chemical Education, 2001, 3(6):II - 1001-4.

[2] Dan G. Algorithms on Stings, Trees, and Sequences: Computer Science and Computational Biology.[J]. Quarterly Review of Biology, 1997, 28(3):41-60.

[3] Weiser M. Some computer science issues in ubiquitous computing[J]. Acm Sigmobile Mobile Computing \& Communications Review, 1993, 36(7):74-84.

[4] Chen, X. (2006). Department of computer science and technology. Journal of Henan Mechanical \& Electrical Engineering College.

[5] Newell A, Simon H A. Computer Science as Empirical Inquiry: Symbols and Search.[J]. Communications of the Acm, 1976, 19(3):113-126.

[6] Dan, Gusfield. "Algorithms on Stings, Trees, and Sequences: Computer Science and Computational Biology.." Quarterly Review of Biology 28.3(1997):41-60.

[7] Chen X. Department of Computer Science and Technology[J]. Journal of Henan Mechanical \& Electrical Engineering College, 2006.

[8] Newell, A., \& Simon, H. A. (1976). Computer science as empirical inquiry: symbols and search.. Communications of the Acm, 19(3), 113-126.

[9] Nori K V, Kumar S. Foundations of Software Technology and Theoretical Computer Science[M]// Springer-Verlag New York, Inc., 1988:xii,361.

[10] Weiser, Mark. "Some computer science issues in ubiquitous computing." Acm Sigmobile Mobile Computing \& Communications Review 36.7(1993):74-84.

[11] Springer-Verlag. Lecture notes in computer science, No.639[J]. Cowell (Ed.), Portability of numerical software (Oak Brook, 2001, 5714. ISBN 978-3-642-04345-1. Springer Berlin Heidelberg(1):15--30.

[12] Freedson P S, Melanson E ,, Sirard J ,. Calibration of the Computer Science and Applications, Inc. accelerometer.[J]. Medicine \& Science in Sports \& Exercise, 1998, 30(5):777-781. 